\title{
Study on Mechanical Behavior and Failure Network of Deep Roadway under Different Lateral Pressure Coefficients
}

\author{
Feng Luo \\ Hebei University of Engineering \\ Yijun Guo \\ Hebei University of Engineering \\ Peidong Xu \\ Hebei University of Engineering \\ Yanglong Diao \\ Hebei University of Engineering \\ Meng Li ( $\square$ Imlm0520@126.com) \\ Hebei University of Engineering https://orcid.org/0000-0001-7725-0241
}

\section{Research Article}

Keywords: deep roadway, shear band, tensile failure, lateral pressure coefficient

Posted Date: March 15th, 2021

DOl: https://doi.org/10.21203/rs.3.rs-294896/v1

License: (c) This work is licensed under a Creative Commons Attribution 4.0 International License. Read Full License 


\section{Abstract}

The failure and instability of roadway is a main disaster with the highest frequency in coal mines. The development of surrounding rock control technology is an important way to ensure mine safety. In order to obtain the failure characteristics of surrounding rock and optimize the support method of the roadway, the numerical simulation and physical simulation were used to investigate the mechanical behavior of deep roadway under different lateral pressure coefficients. The evolution mechanism of meso tensile-shear cracks in excavation damaged zone (EDZ) were deeply revealed. The results show that the shear bands which are basically in the form of sliding spiral extends from the two sidewalls to the roof and floor with the increase of lateral pressure coefficient, and develop to the deep surrounding rock. The "crescent-shaped" tensile failure zones generate in the roof and floor when $\lambda<1$, and gradually decrease with the increase of horizontal stress. When $\lambda=1$, the failure pattern around the arch and right angle sides are different influenced by the shape of different side. Under the special stress environment of high deviatoric stress, the pattern of plastic zone will lead to butterflylike failure mode induced by the stress relief of excavation. Judged from the curves of tangential and deviatoric stress, the surrounding rock in the two sidewalls, the roof and floor are greatly damaged under $\lambda<0.75$ and $\lambda>1.5$ respectively. The verification of the numerical simulation experiment is proved by the similar material simulation experiment.

\section{Introduction}

With the increasing of coal mining depth, the problem of large deformation of surrounding rock in the deep is becoming increasingly serious. Once the underground space is excavated, the redistribution of in-situ stress and the varying degrees of rock damage will inevitably occur surrounding the roadway. The post-peak failure and deformation characteristics have always been an important topic and the mechanical behavior are quite complex as shown in Fig. 1. The lateral pressure coefficient is the ratio of horizontal stress to vertical stress, which is one of the important parameters reflecting the in-situ stress state of rock mass. It is particularly important to explore the mechanical behavior and failure characteristics of surrounding rock under complex stress environment, which is of great significance to safety of roadway.

In terms of the research on lateral pressure coefficient based on FEM, some scholars (Tan et al. 2020; Wang et al. 2019; Hou et al. 2015; Wang et al. 2015; Wang et al. 2019; Yang et al. 2019) studied the stress and deformation distribution of roadway under different lateral pressure coefficients. Dong et al. (2019) investigated the approximate analytical range of plastic zone of surrounding rock in two-way unequal pressure roadway through the approximate implicit method and verified by Abaqus finite element software. Yu et al. (2019) used PFC discrete element software to explore the influence of vertical stress and lateral pressure coefficient on different energy characteristics. The usage of strain softening model is very important for the simulation of tensile-shear bands. The strain softening model was used to qualitatively and quantitatively analyze the failure of roadway (Cao et al. 2019; Guan et al. 2020; Li et al. 2019; Kang et al. 2021; Zhou et al. 2009), which showed that the strain softening model can better simulate the dynamic failure characteristics of surrounding rock of roadway. Lu et al. (2010) obtained the softening law of post-peak mechanical parameters of weak rock through establishing the subsequent yield surface model of weak rock characterized by two state parameters (generalized cohesion and generalized internal friction angle). Wang et al. (2019) introduced Weibull distribution function to study the influence of internal friction angle on the zonal disintegration of surrounding rock of gradually excavated arch roadway. Wang et al. (2013) established a statistical damage constitutive model which can simulate the whole process of strain-softening rock deformation, and proved its rationality and feasibility. Wang et al. (2012) obtain the elastic modulus of rock under various damage state for the failure characteristics of deep roadway, the butterfly failure theory was adopted (Guo et al. 2020 and Ma et al. 2019), which provided a new method and idea for studying the mechanical behavior of underground rock mass. The process and characteristic evolution of zonal disintegration in roadway surrounding rock failure were analysed (Luo et al. 2012; Wang et al. 2010; Gao et al. 2010), Bai et al. (2019) developed a continuous-discontinuous method that coupled Lagrange element method, deformable body discrete element method and virtual crack model and considered quadrilateral element cracking along diagonal line. This innovative method was used to simulate the deformationcracking process of void model under different confining pressures.

In general, the studies on the macroscopic pattern characteristics of plastic zone of surrounding of the roadway are deeply investigated. However, there are few references about the meso-failure network of tensile-shear cracks in EDZ. The meso-failue characteristics has very important practice guidance for the directional bolt support. Based on the previous studies, the plane strain models were used to investigate the influence of different lateral pressure coefficients on the stress distribution and failure network of the surrounding rock by FEM numerical simulation and similar material simulation, which can accurately predict the distribution and evolution of the tensile-shear band in EDZ. The research results will provide significant practice value for the in-site engineering.

\section{Establishment Of The Model And Variable Determination 2.1. Failure zoning of roadway surrounding rock}

Due to the roadway excavation, the redistribution of in-situ stress appears in the surrounding rock. A series of deformation and failure induced by the stress pressurization and unloading in surrounding rock forms. According to the failure characteristics and the mechanical state, the surrounding rock could be zoned as shown in the Fig. 2 (a). The surrounding rock will get into the strain softening stage after reaching the peak stress. In the strain softening stage, the bearing capacity of surrounding rock is not completely lost, but gradually decreases with the increase of the shear strain until it reaches the residual. 
In this zone, the surrounding rock is deeply destroyed by tensile and shear stress. However, the failure network is not disordered, but shows obvious directional effect according to the direction of the maximum principal stress. The study on the distribution and evolution of meso-cracks in the EDZ will promote the research on the failure mechanism of surrounding rock from macro to meso scale, and has great significance for the research and development of directional targeted control method of the surrounding rock. The conceptualized characteristics of meso tensile-shear failure in EDZ under hydrostatic pressure as shown in Fig. 2 (b).

\subsection{Establishment of calculation numerical model}

The radius of the simulated roadway is $2 \mathrm{~m}$. According to the elastic theory, the influence radius of excavation-induced stress in practical engineering is approximate 4.5 times of roadway radius. In order to ensure that there was enough computing space, and not affected by the boundary, 7.5 times of the roadway radius $(15 \mathrm{~m})$ had been selected as the half size of the calculation domain. The size of the calculation model is $30 \mathrm{~m} \times 30 \mathrm{~m}$. Within the range of stress redistribution, the calculation model and mesh division of the arched roadway are shown in Fig. 3 . The 14 stress monitoring points were set every $0.5 \mathrm{~m}$ in the roof and right sidewall of the surrounding rock respectively.

\subsection{Strain softening model and the selection of rock parameter}

The plane strain model of roadway was established by strain softening constitutive model which was embedded in FLAC3D numerical simulation software. Strain softening is an anamorphism process after the plastic yield of material, which is becoming ever more inelastic. In the numerical simulation, the material is weakened by gradually reducing the cohesion and internal friction angle. The detailed parameters of the numerical simulation model are shown in Table 1, and the bulk modulus and shear modulus as the mechanical properties of rock materials can be obtained according to the Young's modulus and Poisson's ratio. The weakening parameters and weakening law are shown in Table 2.

Table 1

Mechanical parameters of numerical simulation (Porathur et al.)

\begin{tabular}{|c|c|c|c|c|c|c|c|c|c|}
\hline Name & $\begin{array}{l}\text { Density } \\
\left(\mathrm{Kg} / \mathrm{m}^{2}\right)\end{array}$ & $\begin{array}{l}\text { Elastic } \\
\text { modulus(GPa) }\end{array}$ & $\begin{array}{l}\text { Tensile } \\
\text { strength(MPa) }\end{array}$ & $\begin{array}{l}\text { Shear } \\
\text { strength(MPa) }\end{array}$ & $\begin{array}{l}\text { Bulk } \\
\text { modulus(GPa) }\end{array}$ & $\begin{array}{l}\text { Shear } \\
\text { modulus(GPa) }\end{array}$ & $\begin{array}{l}\text { Cohesion } \\
\text { (MPa) }\end{array}$ & $\begin{array}{l}\text { Friction } \\
\text { angle }\left(^{\circ}\right)\end{array}$ & $\begin{array}{l}\text { Poisson } \\
\text { ratio }\end{array}$ \\
\hline Sandstone & 2500 & 10 & 1.3 & 3.2 & 6.67 & 4 & 3.2 & 34 & 0.25 \\
\hline
\end{tabular}

Table 2

Change in cohesion and friction angle with shear

strain

\begin{tabular}{|lll|}
\hline Shear strain & Cohesion/MPa & Friction angle/ $^{\circ}$ \\
\hline 0 & 3.2 & 34 \\
\hline 0.005 & 3.0 & 33.5 \\
\hline 0.01 & 2.8 & 33 \\
\hline 0.05 & 0 & 29 \\
\hline
\end{tabular}

\subsection{Scheme determination of simulation}

In this scheme, the surrounding rock was assumed as an uniform and isotropic strata in FLAC3D finite difference software. The far-field stress is hydrostatic pressure without creep and viscosity behavior. The plane strain model was restrain along the axial direction. The model boundaries were constrained by the displacement control. The loading was carried out by the far-field stress $\sigma_{\mathrm{v}}$ and $\sigma_{\mathrm{h}}$ of in-situ stress, as shown in Fig. 2. Assume the buried depth of the roadway is $800 \mathrm{~m}$, the vertical stress is $20 \mathrm{MPa}$. The lateral pressure coefficient $\lambda$ is $0.25,0.5,0.75,1,1.25,1.5,1.75,2,2.25,2.5$. The values of $\sigma_{\mathrm{v}}$ and $\sigma_{\mathrm{h}}$ are shown in Table 3 . By the implementation of this scheme, with the changing of lateral pressure coefficient, the stress distribution and evolution of surrounding rock and plastic zone pattern of arched roadway were compared and analyzed.

Table 3

In-situ stress conditions

\begin{tabular}{|lllllllllll|}
\hline Lateral pressure coefficient & 0.25 & $\mathbf{0 . 5}$ & $\mathbf{0 . 7 5}$ & $\mathbf{1}$ & $\mathbf{1 . 2 5}$ & $\mathbf{1 . 5}$ & $\mathbf{1 . 7 5}$ & $\mathbf{2}$ & $\mathbf{2 . 2 5}$ & $\mathbf{2 . 5}$ \\
\hline Vertical stress $\left(\sigma_{\mathrm{v}}\right) / \mathrm{MPa}$ & 20 & 20 & 20 & 20 & 20 & 20 & 20 & 20 & 20 & 20 \\
\hline Horizontal stress $\left(\sigma_{\mathrm{h}}\right) / \mathrm{MPa}$ & 5 & 10 & 15 & 20 & 25 & 30 & 35 & 40 & 45 & 50 \\
\hline
\end{tabular}

\section{Analysis And Discussion On Numerical Simulation Results}

\subsection{Analysis on failure characteristics of surrounding rock under different lateral pressure coefficients}


Figure 4 (a-j) shows the pattern of plastic zone surrounding the deep roadway. With the increase of lateral pressure coefficient, the surrounding rock shows the following characteristics.

(1) When $\lambda<1$, there are different degrees of shear slip bands in roadway sidewalls. With the increase of lateral pressure coefficient, the shear slip zone of roadway sidewalls is more obvious. It can be seen that the shear failure occurs at both corners of the floor firstly, forming a "crab-claw shaped" failure zone which extends to the middle of the floor with the increase of the lateral pressure coefficient. When the lateral pressure coefficient is 0.25 , butterfly-like plastic zone appears around the deep roadway.

(2) When $\lambda=1$, the surrounding rock is in a bidirectional isobaric stress field, and the plastic zone of the surrounding rock is evenly distributed. Influenced by the shape of different side, the failure pattern around the arch and right angle sides are different. The order of failure depth of surrounding rock from shallow to deep is the two corners, the arch, the two sidewalls and the floor. A square-shaped plastic zone is formed around the roadway, and the shear slip failure zone occurs in the whole sides of the roadway.

(3) When $\lambda>1$, the plastic zone form of surrounding rock is elliptical, and with the increase of lateral pressure coefficient, the plastic expansion of roof and floor is more significant than that of sidewalls. When $\lambda$ further increases, shear slip bands which expands to the deep surrounding rock generates gradually in the surrounding rock of arch roof and floor. There are obvious intersections of the shear bands in this area. Therefore, when $\lambda>1$, the failure type around the arch and floor of the roadway under this in-situ stress is mainly shear failure.

\subsection{Failure mechanism analysis of surrounding rock under different lateral pressure coefficients}

The tensile and compressive strength is an important mechanical property of rock. In the rock mass, the magnitude of tensile and compressive strength will directly affect the stability of surrounding rock. In the FLAC3D numerical simulation, the directions of shear failure and tensile failure of rock mass has a significant relationship with the directions of maximum principal stress and minimum principal stress. Therefore, a clear understanding of the distribution of maximum principal stress and minimum principal stress is of great significance in the judgment of tensile and shear failure in rock mass. The distribution of tensile and compressive stress was analyzed by the principal stress contour under different lateral pressure coefficients, so as to explain the mechanical behaviors and failure mechanism of plastic zone of surrounding rock.

(1) Failure characteristics of roadway surrounding rock $(\lambda=0.25)$

When the lateral pressure coefficient is 0.25 , the vertical stress is 4 times that of the horizontal stress. It can be seen from the minimum principal stress (Min-P-S, only used in figure caption, See Fig. 5 (b)) and maximum principal stress(Max-P-S, only used in figure caption, See Fig. 5 (c)) contours that the tensile stress is mainly distributed in the shallow part of surrounding rock, and the shear bands is mainly distributed in the two sidewalls of the roadway. According to the distribution pattern of plastic zone(P-Z, only used in figure caption, See Fig. 5 (a)), under the high vertical stress, the "crescentshaped" tensile failure zones generate in the roof and floor respectively. The good stress state of arch structure makes the tensile failure of arch roof far less than that of floor. High vertical stress is transmitted to the two sidewalls of the roadway after excavation, so that a "crab-claw shaped" stress unloading area, which includes the conjugate shear bands and radial tensile failure, is formed in the two sidewalls. Under the condition of the lateral pressure coefficient of 0.25 , because of the high differential stress magnitude between the two principle stresses, the stress state is significantly uneven in the surrounding rock. Induced by the artificial excavation of roadway, large-scale shear failure originated from the concentration point of the roadway is prone to occur in the strata. A butterfly-like shear failure zone, just like the X-shaped failure mode in the UCS experiment, generates around the roadway, as shown in the Fig. 5 (a). This may be the main reason for the large area dynamic damage in the roadway.

(2) Failure characteristics of roadway surrounding rock $(0.5 \leq \lambda \leq 1)$

1) When the lateral pressure coefficient is 0.5 , tensile failure under high vertical stress still generate in the roof and floor, as shown in Fig. 6 (a). It is found that the tensile stress zone is significantly reduced compared with that when $\lambda$ is 0.25 , but the tensile failure of floor is much greater than that in the roof, and tensile stress area still exists in the shallow part of the two sidewalls. The shear slip bands mainly appear in the sidewalls, and the "crabclaw shaped" failure zone formed in the floor gradually decreases and closes to the middle of the floor.

2) With the further increase of horizontal stress, when the lateral pressure coefficient is 0.75 , according to the maximum and minimum principal stress distribution (See Fig. $6(\mathrm{e}, \mathrm{f})$ ), the tensile failure area around the roadway decreases greatly. Meanwhile, the shear slip bands around the roadway increase, and a small amount of shear failure occurs in roof. The "crab-claw shaped" failure area continues to expand in the floor under the influence of horizontal stress increasing, as shown in the Fig. 6 (d).

3) When the lateral pressure coefficient is 1 , the roadway is in the state of bidirectional isobaric stress. According to the distribution pattern and contour of the plastic zone and principal stress as shown in the Fig. $6(\mathrm{~g}-\mathrm{i})$, shear slip bands occur all around the whole roadway, and the plastic failure zone is approximately square distribution. The "crab-claw shaped" shear slide bands penetrates the floor strata of the roadway. An "inverted-triangle" nonfailure zone surrounded by the shear slip cracks above the penetration zone are formed.

Therefore, when the lateral pressure coefficient is between 0.5 and 1 , the plastic failure area in the roof and floor is significantly smaller than that of sidewalls. With the increase of lateral pressure coefficient, the tensile failure area mainly occurs in the roof and floor and gradually decreases. Shear slip

Page $4 / 15$ 
band is the main form of shear failure in the two sidewalls.

(3) Failure characteristics of roadway surrounding rock $(1.25 \leq \lambda \leq 2)$

1) When the lateral pressure coefficient is 1.25, the horizontal stress is higher than the vertical stress. From the principal stress contour (See Fig. 7 (b-c)), it can be seen that the tensile stress area generates in the floor of roadway, and the V-shaped plastic failure area is formed in the deep surrounding rock of floor. In the distribution pattern of the plastic zone, it is found that the shape of roof forms a stable arch structure when the horizontal stress is greater than the vertical stress, and the failure area of the floor is larger than that of the roof.

2) When the lateral pressure coefficient is 1.5 , the plastic zone of roadway further expands, but the plastic failure zone of floor expands faster than that of roof. From the principal stress contour, as shown in Fig. 7 (e-f), it can be seen that the roof and floor have obvious tensile stress due to high horizontal stress and deep shear action, which makes the roof and floor have obvious tensile-shear mixed failure area, and the anti-arch failure zone formed in the floor surrounding rock is more obvious.

3) When the lateral pressure coefficient is 1.75 , the radial tensile failure zones and shear slip bands of the roof and floor become larger, and the number of shear slip bands increases, as shown in Fig. 7 (g-i).,

4) When the lateral pressure coefficient is 2 , the shear slide bands of roof and floor gradually expand to the deep surrounding rock. The failure area of the floor is obviously faster than that of roof. Induced by the increase of high horizontal stress, the shear slip bands of the floor are accelerated to expand to the deep surrounding rock, and the deep rock masses are cut to heterogeneous fracture network, as shown in Fig. 7 (j-I).

In summary, when the lateral pressure coefficient is between 1 and 2, with the increase of lateral pressure coefficient, the plastic zone expansion speed in the roof and floor is more obvious. The number of shear slip bands in the two sidewalls decrease and increase in the roof and floor gradually. The tensile failure zone is mainly concentrated in the arch shoulder and floor corners.

(4) Failure characteristics of roadway surrounding rock $(\lambda=2.25$ and $\lambda=2.5)$

When the lateral pressure coefficient is between 2 and 2.5, through the plastic zone pattern and principal stress contour (See Fig. 8), it can be clearly seen that the tensile-shear failure is mainly concentrated in the roof and floor. A butterfly-like failure of the floor, which is perpendicular to the case of $\lambda$ $=0.25$, generates in the deep surrounding rock. The surrounding rock in the roof shows a trend of shear-slip spiral bands to butterfly-like failure. The failure zone of the roadway further expands to the deep, and develops rapidly with the increase of horizontal stress. At the same time, the failure of the surrounding rock under high deviatoric stress is directional, that is, the butterfly wing is the maximum failure depth and width of the surrounding rock and located at the position of $45^{\circ}-\varphi / 2$ with the maximum principle stress.

\subsection{Distribution characteristics of the stress in the surrounding rock under different lateral pressure coefficient}

(1) The tangential stress evolution of the sidewall and roof

For the tangential stress distribution characteristics curve of roof and right sidewall under different lateral pressure coefficients, the peak strength and abutment pressure are sensitive to the change of lateral pressure coefficient. For the sidewall (See Fig. 9 (a)), when $\lambda \geq 1.5$, the tangential stress of surrounding rock is generally lower than the original stress, and the high horizontal stress makes the surrounding rock in a residual failure state. When $0.25<\lambda<1.5$, with the increase of lateral pressure coefficient, the range of limit equilibrium zone gradually decreases, the range of elastic zone gradually increases, and the stress peak position of the monitoring points in surrounding rock shifts towards the direction of the roadway (See Fig. 10 (a)). For the roof (See Fig. 9 (b)), when $\lambda<0.75$, the tangential stress are no obvious differences with the horizontal stress. When $\lambda>0.75$, with the increase of the lateral pressure coefficient, the limit equilibrium zone in the roof gradually becomes larger, the elastic zone becomes smaller, and the position of the stress peak shifts to the deep part of the surrounding rock, as shown in Fig. 10 (b). In the summary, when $\lambda>1.75$, the surrounding rock of the sidewalls and roof is significantly affected by the lateral pressure coefficient.

(2) The deviatoric stress evolution of the sidewall and roof

Figure11 shows the distribution characteristics of deviatoric stress of the roof and right sidewall under different lateral pressure coefficients. The deviatoric stress distribution characteristics is roughly similar to the tangential stress, but there are also some differences. For the sidewalls of the roadway (See Fig. 11 (a)), when $\lambda>1.5$, the deviatoric stress has a little change and keep a straight line basically. When $\lambda<1.5$, the deviatoric stress curve first increases and then decreases. The position of the concentrated deviatoric stress peak transfers from the deep to the shallow part of the surrounding rock with the increase of lateral pressure coefficient, indicating that the increase of horizontal stress reduce the failure range, which is good for the stability of the sidewalls. For the roof (See Fig. 11 (b)), when $\lambda<0.75$, there is no obvious fluctuation of the deviatoric stress. When $\lambda>0.75$, the deviatoric stress increases first and then decreases. The failure range and the concentrated deviatoric stress of arch roof expands to the deep with the increase of lateral pressure coefficient. Different from the two sidewalls, the increase of horizontal stress aggravates the damage of the roof and has significant effects on its stability. 


\subsection{Variation characteristics of the deviatoric stress with the different distance away from the roadway}

The curve of deviatoric stress of surrounding rock with the different distance away from the roadway is shown in Fig. 12. In the deviatoric stress distribution curve of sidewalls (See Fig. 12 (a)), it can be seen that obvious deviatoric stress concentration appears in the surrounding rock of sidewall in the condition of $\lambda=2$. With the increase of the distance between the monitoring point and the surface of the roadway, the concentrated deviatoric stress increases first and then decreases. When the distance away from the roadway is $4 \mathrm{~m}$, the deviatoric stress concentration reaches the maximum. For surrounding rock in the roof (See Fig. 12 (b)), with the increase of lateral pressure coefficient, the concentrated deviatoric stress gradually transfers to the deep, so the tensile-shear failure area caused gradually transfers to the deep surrounding rock.

\section{Physical Verification Of Similar Material Simulation}

\subsection{Design of similar material simulation experiment}

1) Self developed experiment device

A Self developed similar material simulation equipment which was composed of hydrostatic system, main steel frame and loading plate was used in the experiment, as shown in Figure13. The model size of the similar material is $500 \mathrm{~mm} \times 180 \mathrm{~mm} \times 500 \mathrm{~mm}$. In order to equalizing pressure, rubber mats had been added between the loading plate and similar materials in this experiment. The model boundary was subjected to biaxial servo loading.

2) Discussion of similar ratio and the loading scheme

Based on the similarity law, combined with the size of similar simulation model, the geometric ratio was determined to be $1: 50$. The similarity ratio calculation can be seen in Formula 1-3. According the parameter of the real rock (See Table. 1), the material ratio of simulation material are shown in Table. 4. The vertical stress and horizontal stress in this simulation is $10 \mathrm{MPa}$ and $20 \mathrm{MPa}$ respectively, the simulated in-situ stress was converted to $0.13 \mathrm{MPa}$ and $0.26 \mathrm{MPa}$. The excavation mode of "loading first, then excavating" was adopt in this experiment. In the loading process, the vertical loading $0.13 \mathrm{MPa}$ (simulated vertical stress) was kept, the horizontal stress $0.26 \mathrm{MPa}$ (simulated horizontal stress) was increased from hydrostatic pressure by using hydraulic system. The experimental process and failure characteristics were recorded.

$$
\begin{gathered}
\alpha_{l}=L_{H} / L_{M}=50 \\
\alpha_{\gamma}=\gamma_{H} / \gamma_{M}=1.5 \\
\alpha_{\sigma}=\sigma_{H} / \sigma_{M}=75
\end{gathered}
$$

In the Formula (1-3), $\mathrm{H}$ represents the model, $\mathrm{M}$ represents the prototype. Where $\mathrm{a}_{1}$ is the size similarity ratio, $\mathrm{a}_{\mathrm{y}}$ is the bulk density similarity ratio, $\mathrm{a}_{\sigma}$ is the stress similarity ratio.

Table. 4 Model parameters and material ratio

\begin{tabular}{|llllll|}
\hline Material ratio & & & & & \\
\hline Proportion number & Total weight /Kg & Sand /Kg & Gypsum /Kg & Lime /Kg & Water /Kg \\
\hline 655 & 84 & 72 & 6 & 6 & 8.4 \\
\hline
\end{tabular}

\subsection{Analysis of material simulation experiment results}

Fig.14 shows the physical experiment results of roadway and the comparison with numerical simulation. When the horizontal loading increases to $0.26 \mathrm{MPa}$, the roof and floor of roadway are seriously damaged. The failure mode is in the form of heart failure, and an inverted V-shaped shear failure area is formed in the roof of roadway. Serious floor heave occurred in the middle of the floor, and large deformation and failure occurred on both corners of the floor. A large range of extrusion deformation is found in the two sides of the roadway, and the displacement of the two sides of the roadway is large.

In the FLAC3D numerical simulation experiment, the yield criterion is still valid, and there are two states: "now" and "past". The "now " state indicates that the failure element is in the yield surface at this moment, and the "past" state indicates that the failure element has left the yield surface and entered the elastic state, so only the "now" state element can play a role in the failure (Chen and Xu, 2008). By comparing the "now" state unit area with the similar simulation experiment failure area, it is found that the failure area forms are consistent and both are heart failure. The inverted $\mathrm{V}$-shaped failure mode of the vault due to shear slip is shown in Fig.14 (a-b), and obvious shear cracks can be found at the bottom of the arch, as shown in Fig.14 $(f-g)$.

\section{Conclusions}


Mechanical behavior and failure network of surrounding rock in deep roadway under different lateral pressure coefficients was studied through numerical simulation and similar material simulation experiments. The following conclusions can be drawn:

1. When the lateral pressure coefficient is 0.25 , the butterfly-like failure zone is prone to generate in sidewalls of deep surrounding rock, and the "crabclaw shaped" failure zone generates in the shallow surrounding rock. When $\lambda>2$, the butterfly-like failure zone is prone to generate in the roof and floor. Both show that under the special stress environment of high deviatoric stress, the pattern of plastic zone will lead to butterfly-like failure mode induced by the stress relief of excavation, and the butterfly wing is the maximum failure depth and width of the surrounding rock and located at the position of $45^{\circ}-\varphi / 2$ with the maximum principle stress.

2. When $\lambda<1$, the shear bands mainly appear in the sidewalls intensively. The tensile failure zone is concentrated in the roof and floor in the form of "crescent-shaped" exceptionally when $\lambda=0.25$ and gradually decreases with the increase of lateral pressure coefficient. When $\lambda=1$, it can be seen that influenced by the shape of different side, the failure pattern around the arch and right angle sides are different. When $\lambda>1$, the shear bands is mainly concentrated in the roof and floor, and the tensile failure area of surrounding rock is large and mainly distributed in the arch shoulders and floor corners of surrounding rock.

3. According to the tangential stress evolution of the sidewall and roof, with the increase of lateral pressure coefficient, the range of limit equilibrium zone gradually decreases of sidewall when $\lambda<1.5$ and gradually increases of roof and floor when $\lambda>0.75$. The surrounding rock of the sidewall and roof is significantly affected by the lateral pressure coefficient when $\lambda>1.75$. According to the deviatoric stress evolution of the sidewall and roof, the increase of horizontal stress reduce the failure range of sidewall when $\lambda<1.5$, which is beneficial to the stability of the sidewall. Different from the two sidewalls, the increase of horizontal stress aggravates the damage of the roof when $\lambda>0.75$, which is not conducive to the stability of the sidewall.

4. The similar material simulation experiment was carried out under the condition of $\lambda=2$. The results of similar material simulation experiment are compared with that of numerical simulation experiment, which can be seen that there are obvious shear bands in the roof and floor of surrounding rock and the large deformation of the sidewalls. Therefore, the verification of the numerical simulation experiment is proved by the similar material simulation experiment.

\section{Declarations}

Funding: This research is financially supported by the National Natural Science Foundation of China $(51804093,52074100)$, Natural Science Foundation of Hebei Province (E2020402048, E2020402041), Science and technology projects for colleges and universities in Hebei Province (BJ2019021), Handan science and technology research and development program (19422091008-32).

Conflicts of interest/Competing interests: The authors declare that they have no known competing financial interests or personal relationships that could have appeared to influence the work reported in this paper.

Availability of data and material: The data that support the finding of this study are available from the corresponding author upon reasonable request.

Code availability: The code that support the finding of this study are available from the corresponding author upon reasonable request.

Authors' contributions: Conceptualization, writing-original draft preparation, experiment design, physical experiment, methodology, software, Feng Luo and Yijun Guo; supervision, writing-review and editing, funding acquisition, Feng Luo; methodology, validation, conceptualization, writing-review and editing, Meng Li; visualization, investigation, Peidong Xu and Yanglong Diao. All authors have read and agreed to the published version of the manuscript.

Ethics approval: Not applicable.

Consent to participate: Not applicable.

Consent for publication: Not applicable.

\section{References}

Bai XY, Wang XB, Ma B, Lu WN, Zhu MZ (2019) Simulation of the crack for the model with a hole under different confining pressures based on a method continuum-discontinuum. Journal of Geomechanics 25(02): 240-248 (In Chinese)

Cao AY, Jing GC, Ding YL, Liu S (2019) Mining-induced static and dynamic loading rate effect on rock damage and acoustic emission characteristic under uniaxial compression. Safety Science 116: 86-96

Chen YM, Xu DP (2008) FLAC/FLAC3D Foundation and Engineering Example. China Water \& Power Press, Beijing, pp 82-83 (In Chinese)

Dong HL, Gao QC, Zhang Z, Chen RB, Liu N (2019) Approximate solution and numerical simulation for plastic zone of roadway surrounding rock under unequal compression in two directions. Journal of China Coal Society 44(11): 3360-3368 (In Chinese) 
Gao FQ, Kang HP, Lin J (2010) Numerical simulation of zonal distrigation of surrounding rock mass in deep mine roadways. Journal of China Coal Society 35(1): 21-25 (In Chinese)

Guan K, Liu HL, Gao ZL, Sun X, Wang JS, Fu QB, Su H (2020) Mechanical response study on the roadway re-pofilling work in squeezing rock mass involving strain-softening behavior. Journal of Mining \& Safety Engineering 2020(1): 115-121 (In Chinese)

Guo XF, Guo LF, Ma NJ, Zhao ZQ, Li C (2020) Applicability analysis of the roadway butterfly failure theotry. Journal of China University of Mining \& Technology 49(4): 646-653+660 (In Chinese)

Hou RB, Wang ZF, Zhang YQ (2015) Influence of lateral pressure coefficient on stability of semicircle arch tunnel. Mining Research and Development 35(10): 51-54 (In Chinese)

Porathur JL, Pal Roy P, Shen BT, Karekal S HIGHWALL MINING Applicability, Design \& Safety. CRC Press/Balkema, Britain, pp 65-66

Li G, Ma Fs, Liu G, Zhao Hj, Guo J (2019) A strain-softening constitutive model of heterogeneous rock mass considering statistical damage and its application in numerical modeling of Deep Roadways SUSTAINABILITY: 11(8)

Lu YL, Wang LG, Yang F, Li YJ, Chen HM (2010) Post-peak strain softening mechanical properties of weak rock. Journal of Mining \& Safety Engineering 29(3): 640-648 (In Chinese)

Luo F, Yang BS, Sun LH, Yang WB, Cui JK, Zhang L (2012) Experimental research on the failure characteristics of surrounding rock under high vertical ground stress. Journal of Mining \& Safety Engineering 29(4): 497-504 (In Chinese)

Ma NJ, Ma J, Zhao ZQ, Guo XF, Shi HY, Qiao JY (2019) Mechanical mechanism and evolution of Xshaped conjugate shear fracturesseism. Journal of China Coal Society 44(6): 1647-1653 (In Chinese)

Sun C, Ao YH, Wang LG (2020) The research on strain-softening characteristics and local fracture law of deep granite roadway. COMPLEXITY 2020

Tan T, Xu MG, Wang P, Zeng WX, Li DF, Yang Y (2020) Study on deformation and failure characteristics of surrounding rock of roadway under different lateral pressure coefficients. Industrial Minerals \& Processing 49(8): 21-25 (In Chinese)

Wang HW, Zhang DQ, Deng DX, Jiang YD, Liu YY (2020) Stress distribution characteristics of roadway surrounding rock damaged zone under nonhydrostatic pressure. Journal of China Coal Society 45(11): 3717-3725 (In Chinese)

Wang HY, Zhang Q, Zhang YJ, Jiang KF (2010) Numerical simulation on disintegration of surrounding rock mass in deep mine roadways. Journal of China Coal Society 35(4): 535-540 (In Chinese)

Wang HP, Cao WG, Wang JY, Zhang C (2013) Study on statistical damage constitutive model of rock with considering full deformation process. Hydrogeology \& Engineering Geology 40(4): 44-49 (In Chinese)

Wang XB, Ma B, Zhang ZH, Lv JG (2019) Numerical simulation on zonal disintegration of surrounding rock of U shape tunnel under progressive excavation and different ratios of axial pressure to lateral pressure. Journal of Disaster Prevention and Mitigation Engineering 39(5): 827-834 (In Chinese)

Wang XB, Tian F, Ma B, Zhang ZH, Pan YS (2019) Numerical simulation of zonal disintegration of surrounding rock at arched tunnel under progressive excavation and different internal frictional angles. Journal of China Coal Society 44(7): 2030-2038 (In Chinese)

Wang YH, Liu YF, Ma HT (2012) Changing regularity of rock damage variable and resistivity under loading condition. Safety Science 50(4): 718-722

Wang ZQ, Wu C, Shi L, Su ZH, Wang P, Huang X (2019) Analysis of surrounding rock stress and plastic zone of two-way unequal pressure circular roadway based on complex variable theory. Journal of China Coal Society 44(S2): 419-429 (In Chinese)

Yang JN, Li QF, Deng HZ, Peng YJ (2019) Correlation analysis of plastic zone between rectangular and circular tunnel: the lateral pressure coefficient less than 1. Mineral Engineering Research 34(4): 10-15 (In Chinese)

Yang XJ, Wang EY, Wang YJ, Gao YB, Wang P (2020) A study of the large deformation mechanism and control techniques for deep soft rock roadways. SUSTAINABILITY: 10(4)

Yi K, Liu ZH, Lu ZG, Zhang JW, Sun ZY (2021) Transfer and dissipation of strain energy in surrounding rock of deep roadway considering strain softening and dilatancy. ENERGY SCIENCE \& ENGINEERING 9(1): 27-39

Yu H, Zhang XJ, Li BY, Chu FJ (2019) Macro-micro mechanical response and energy mechanism of surrounding rock under excavation disturbance. Journal of China Coal Society: 1-10, https://doi.org/10.13225/j.cnki.jccs.2019.1482 (In Chinese) 
Zhou JW, Xu WY, Li MW, Zhou XQ, Shi C (2009) Application of rock strain softening model to numerical analysis of deep tunnel. Journal of Mining \& Safety Engineering 28(6): 1116-1127 (In Chinese)

\section{Figures}

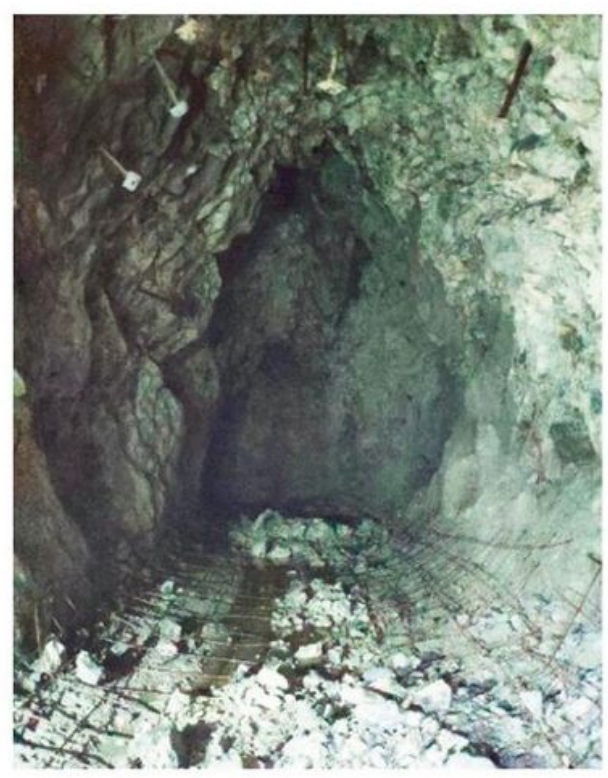

(a) "V-shaped" failure of the roof

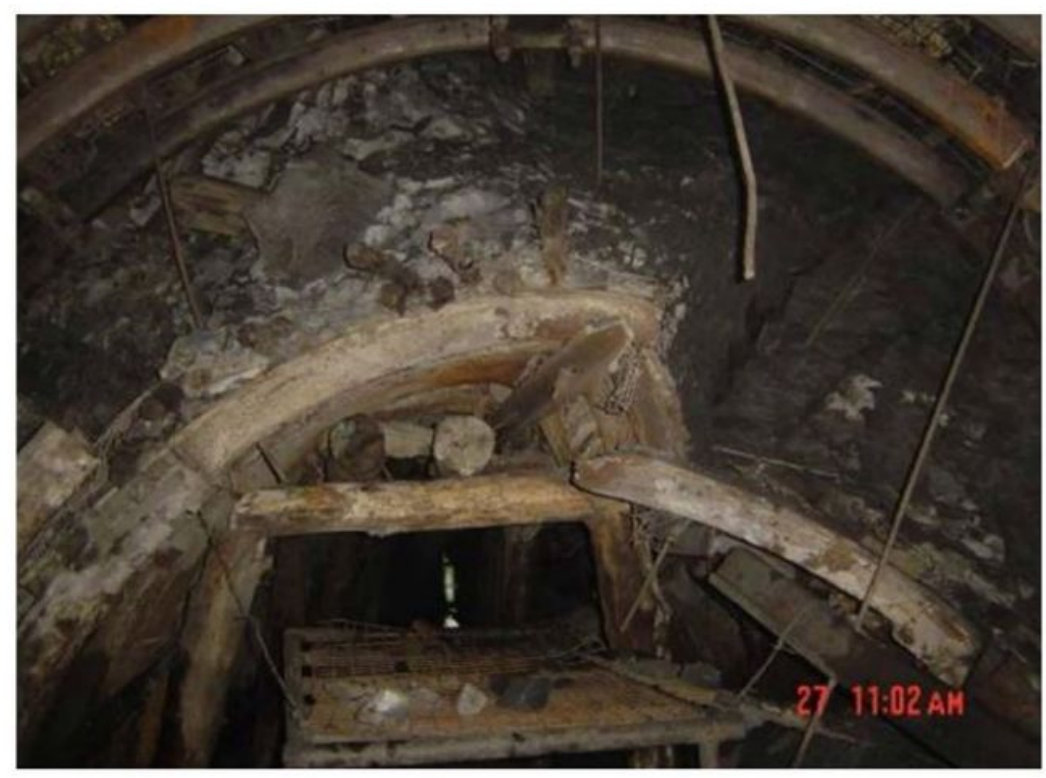

(b) Large deformation of surrounding rock

\section{Figure 1}

Failure characteristics of the surrounding rock (a. Sun et al. 2020; b. Yang et al. 2020)

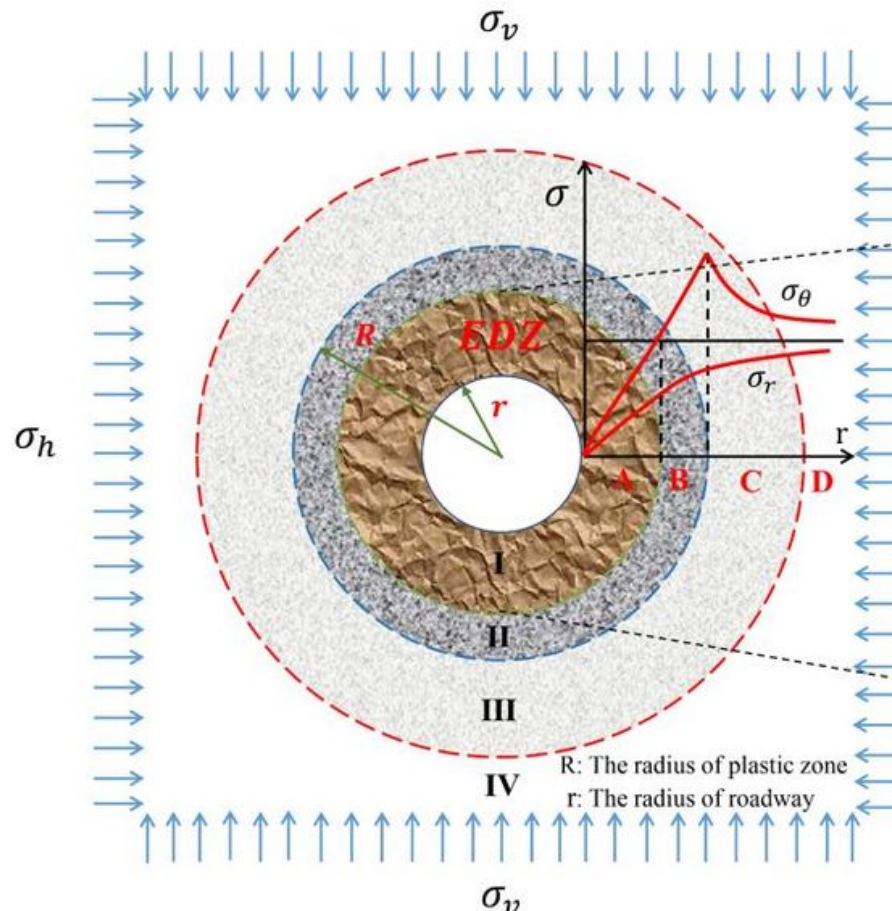

(a) The failure zoning

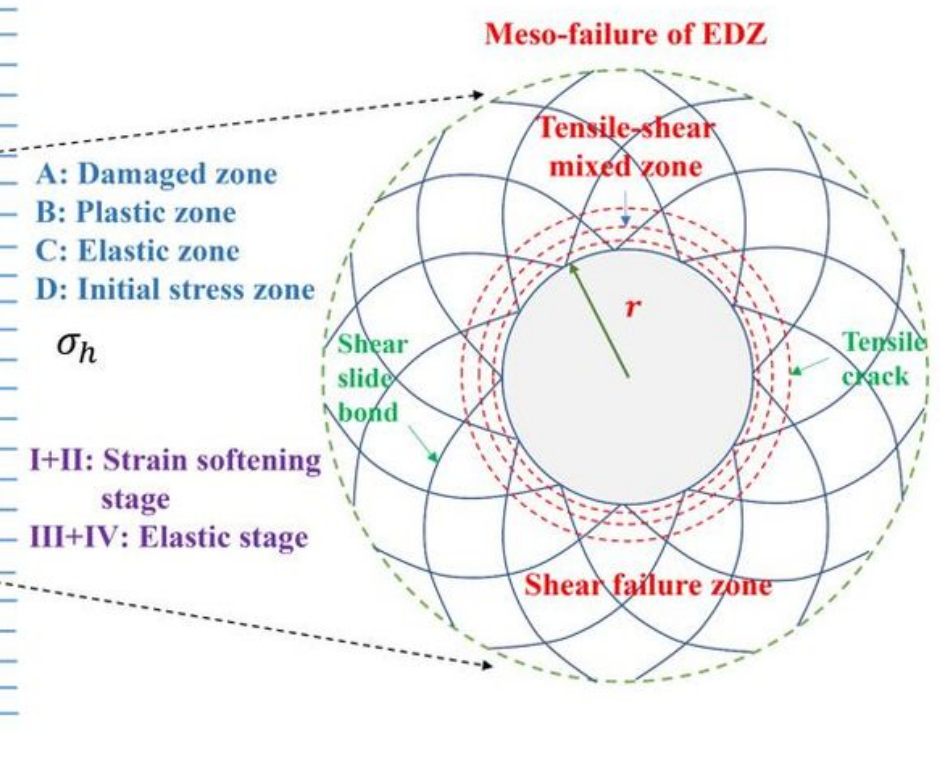

(b) The meso-failure of EDZ

Figure 2

The failure zoning of surrounding rock 


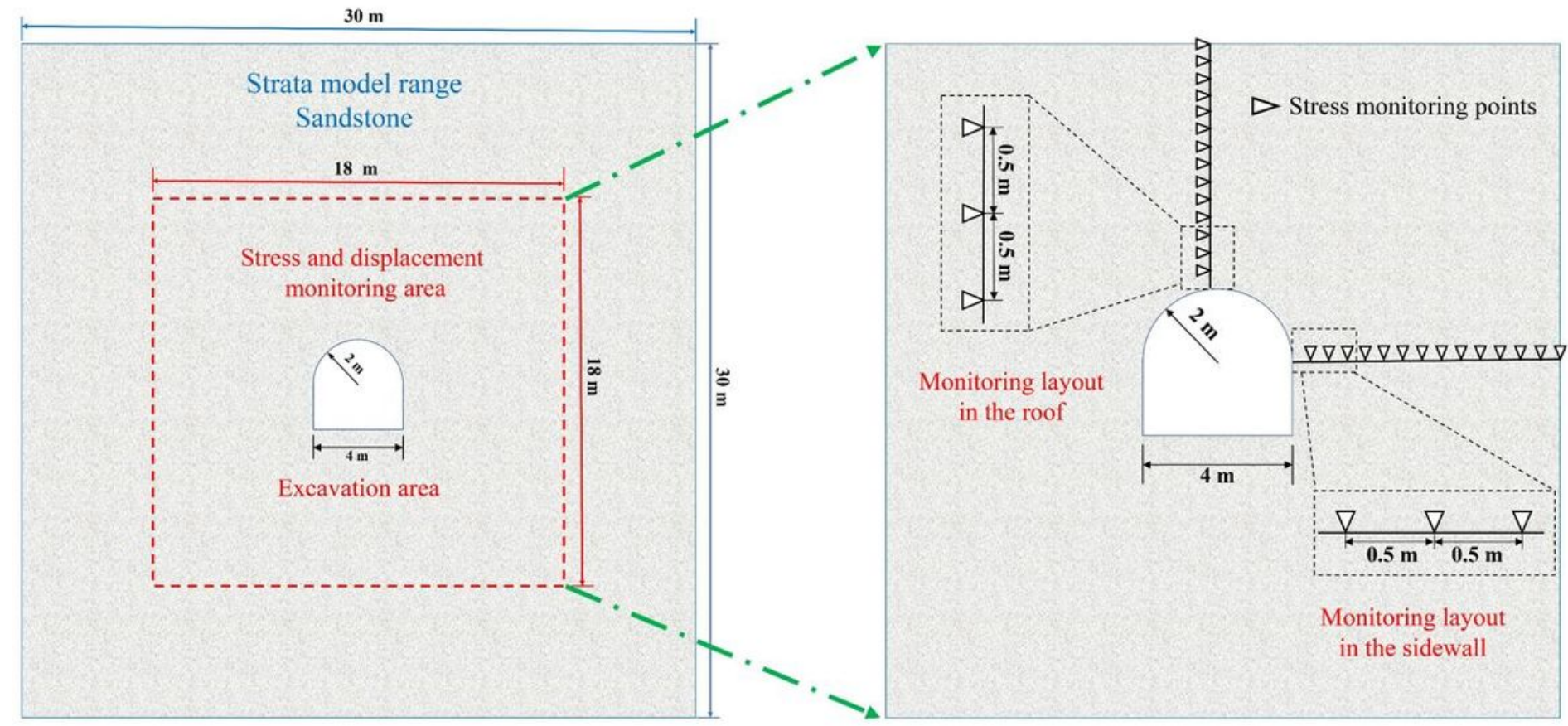

\section{Figure 3}

Numerical calculation model

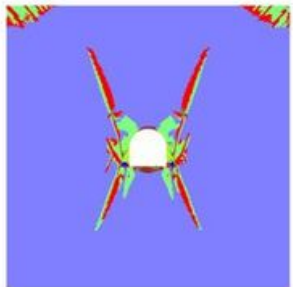

(a) $\lambda=0.25$

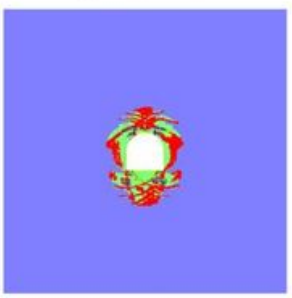

(f) $\lambda=1.5$

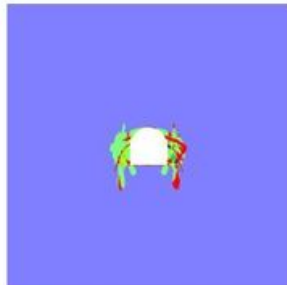

(b) $\lambda=0.5$

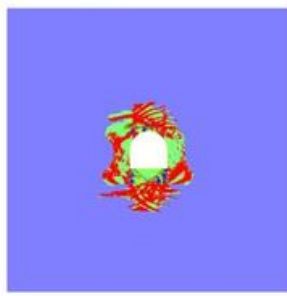

(g) $\lambda=1.75$

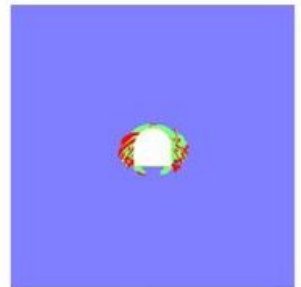

(c) $\lambda=0.75$

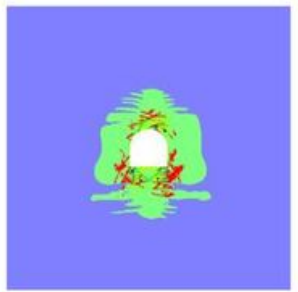

(h) $\lambda=2$

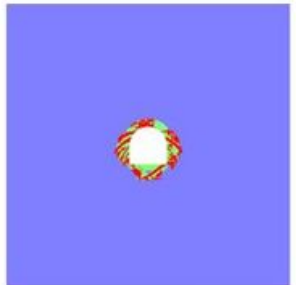

(d) $\lambda=1$

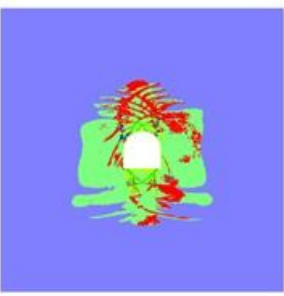

(i) $\lambda=2.25$

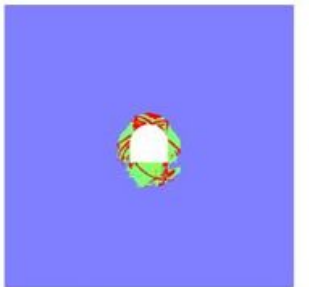

(e) $\lambda=1.25$

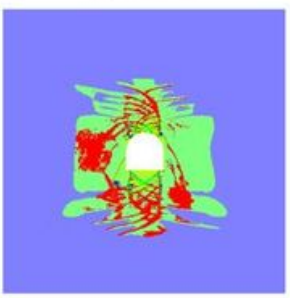

(j) $\lambda=2.5$
None

Shear-n

Shear-n shear-p

Shear-n tension-n

Shear-p

\section{Figure 4}

Plastic zone distribution of surrounding rock under different lateral pressure coefficients
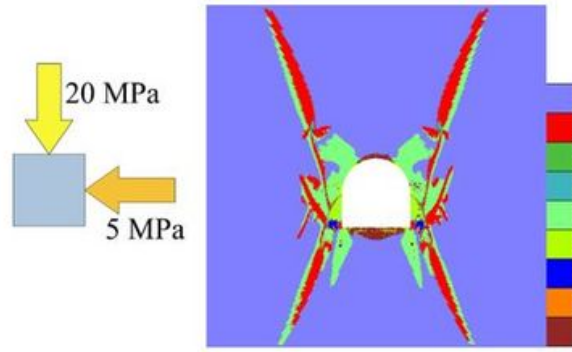

(a) P - Z
None

Shear-n

Shear-n shear-p

Shear-n

Shear-p

Shear-p tension-p

Tension-n shear-p

Tension- $n$ tension- $p$

Tension-p

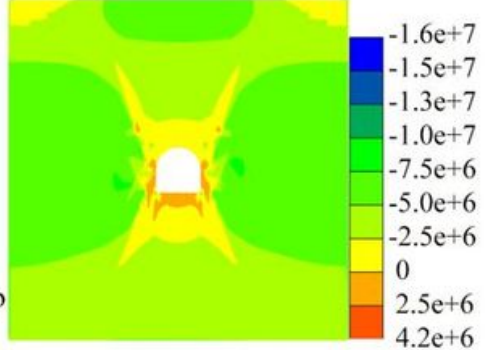

(b) Min - P - S(Pa)

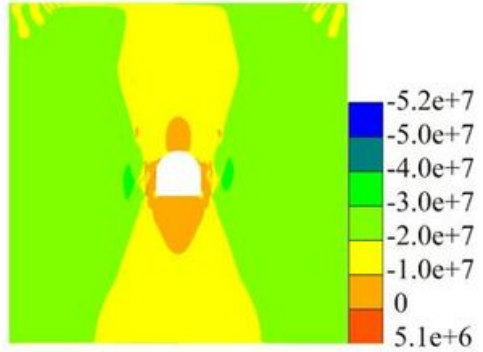

(c) Max - P - S(Pa)
Shear-p tension-p

Tension- $n$ shear-p

Tension-n Tension-p

Tension-p 


\section{Figure 5}

Plastic zone and principal stress distribution of roadway surrounding rock when $\lambda=0.25$
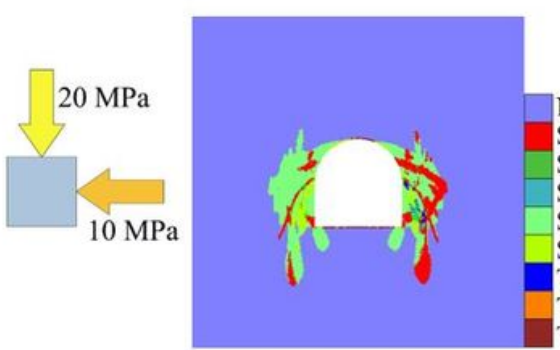

(a) P - Z

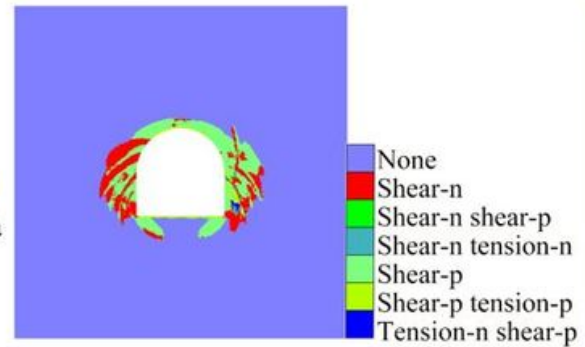

(d) P - Z

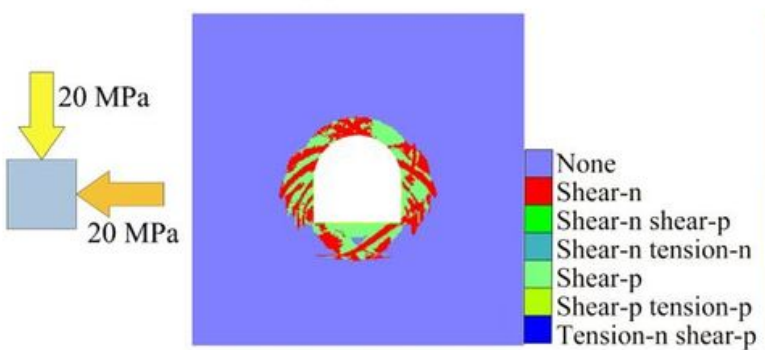

(g) P - Z

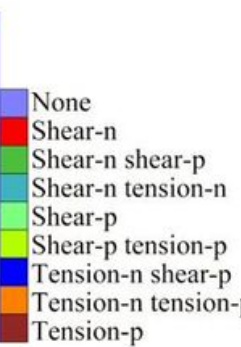

ension-p

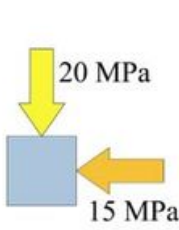

(g) $P-Z$

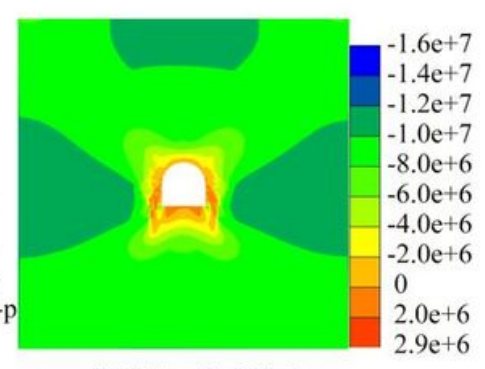

(b) Min - P - S(Pa)

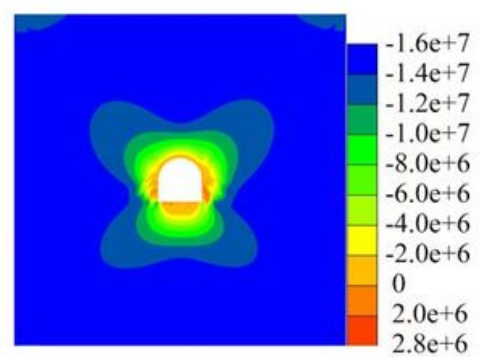

(e) Min - P - S(Pa)

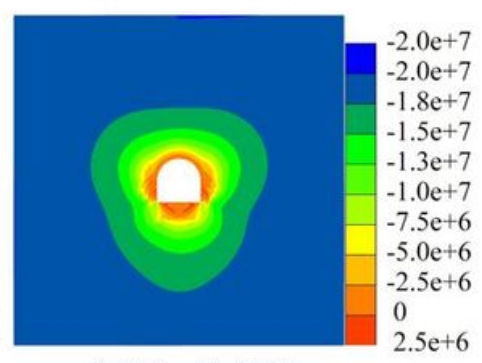

(h) Min - P - S(Pa)

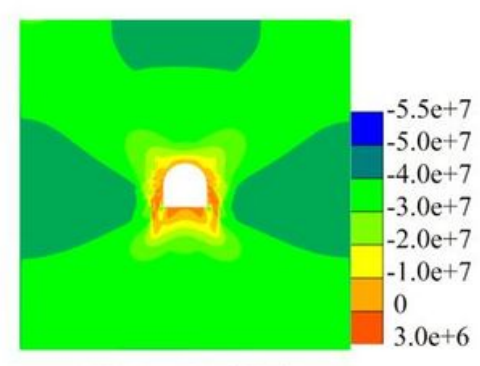

(c) $\mathrm{Max}-\mathrm{P}-\mathrm{S}(\mathrm{Pa})$

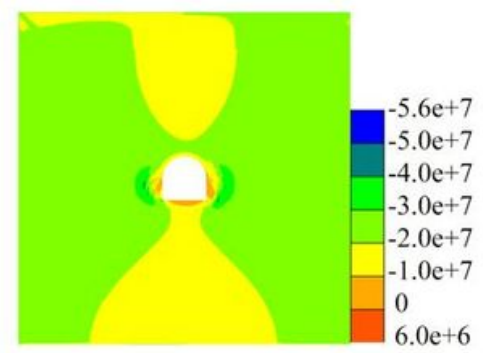

(f) Max - P - S(Pa)

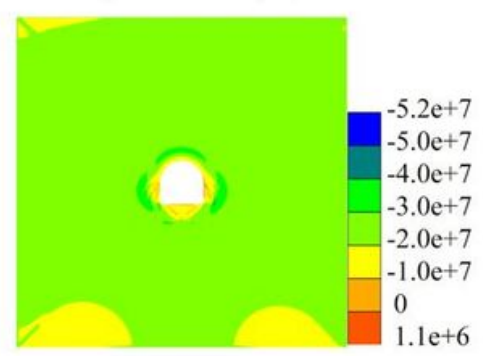

(i) $\mathrm{Max}-\mathrm{P}-\mathrm{S}(\mathrm{Pa})$

\section{Figure 6}

Plastic zone and principal stress distribution of roadway surrounding rock when $0.5 \leq \lambda \leq 1$ 

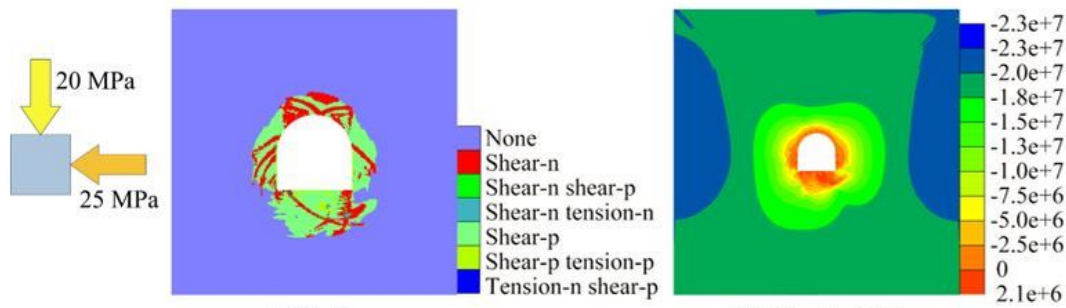

(a) P - Z
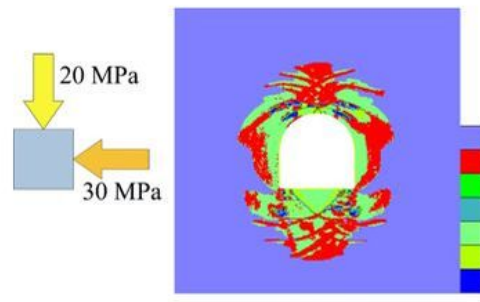

(d) P - Z

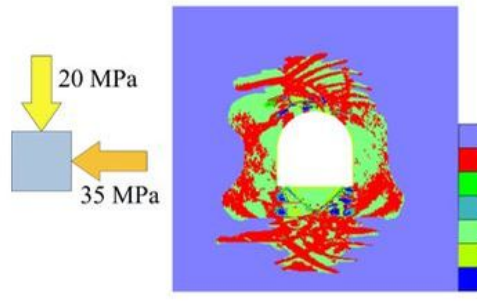

(g) P - Z

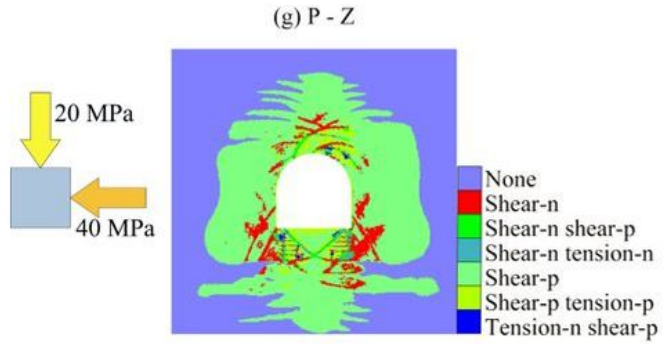

(j) P - Z

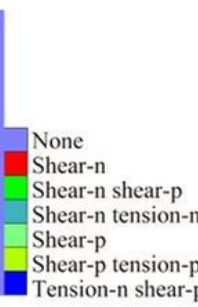

ension-n shear-
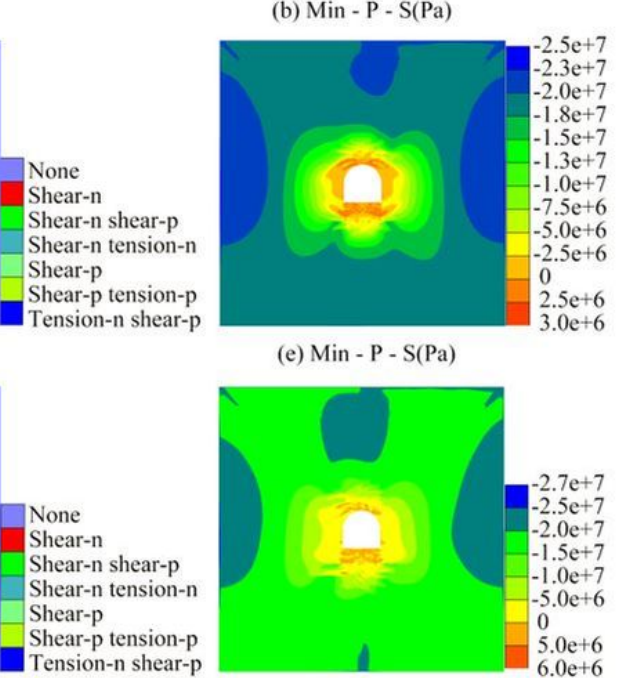

(e) Min - P - S(Pa)

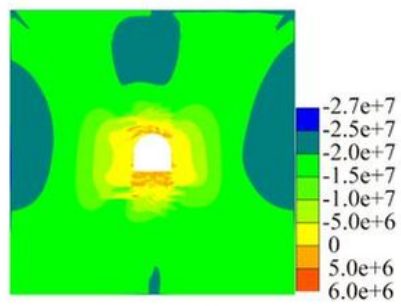

(h) Min - P - S(Pa)

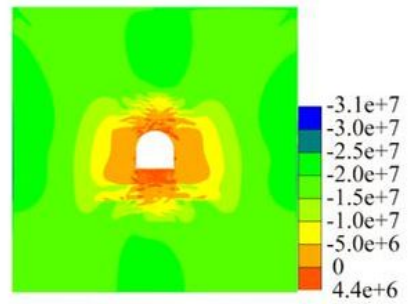

(k) Min - P - S(Pa)

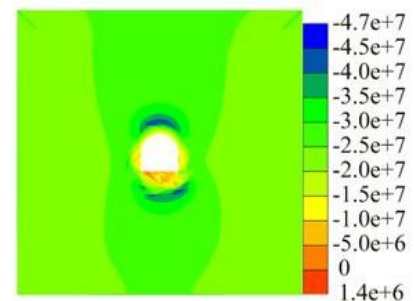

(c) Max - P - S(Pa)

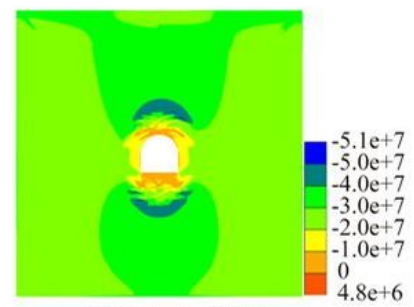

(f) Max - P - S(Pa)

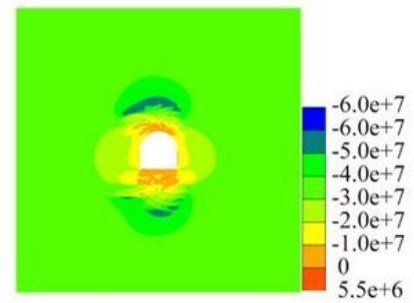

(i) $\mathrm{Max}-\mathrm{P}-\mathrm{S}(\mathrm{Pa})$

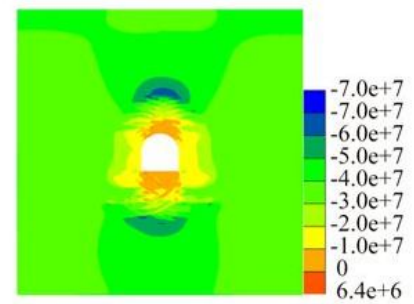

(1) Max - P - S(Pa)

Figure 7

Plastic zone and principal stress distribution of roadway surrounding rock when $1.25 \leq \lambda \leq 2$
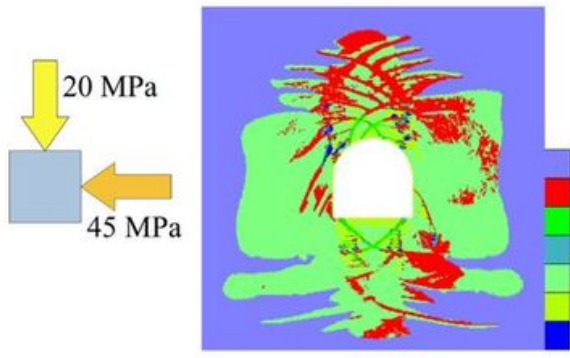

(a) $\mathrm{P}-\mathrm{Z}$
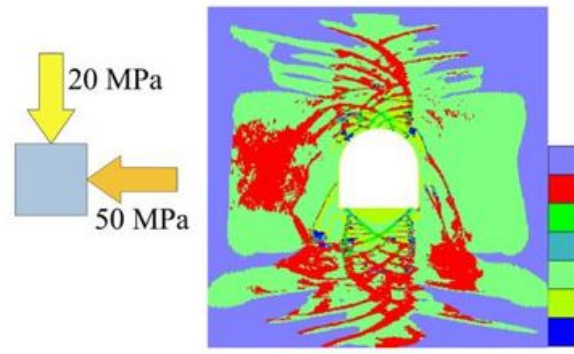

(d) P - Z

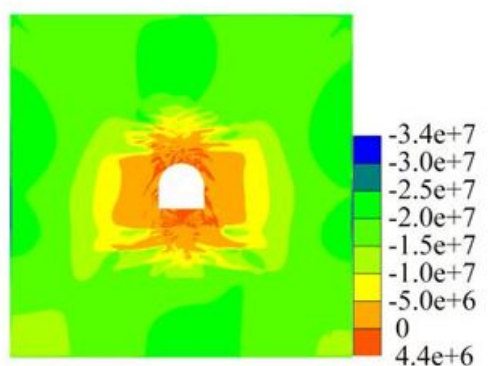

(b) $\mathrm{Min}-\mathrm{P}-\mathrm{S}(\mathrm{Pa})$

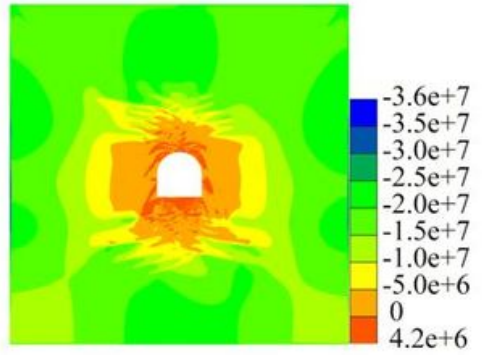

(e) Min - P - S(Pa)

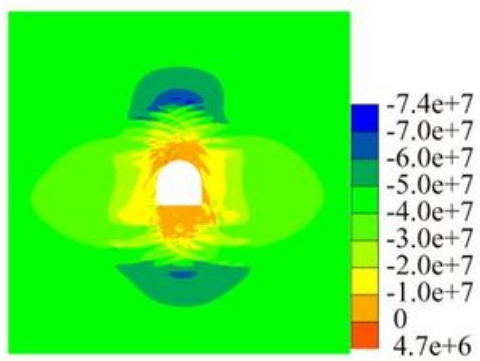

(c) $\mathrm{Max}-\mathrm{P}-\mathrm{S}(\mathrm{Pa})$

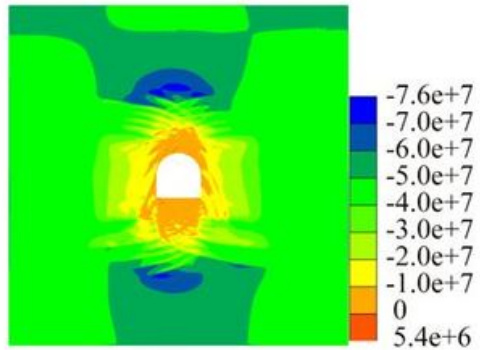

(f) $\mathrm{Max}-\mathrm{P}-\mathrm{S}(\mathrm{Pa})$ 


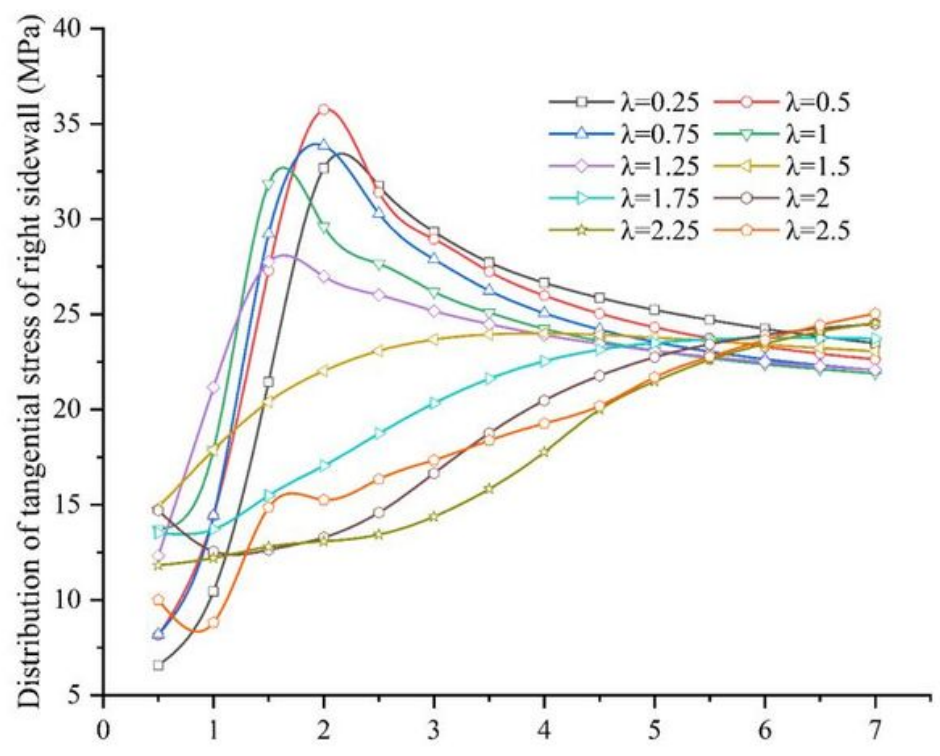

Different radial distence away from the right sidewall $(\mathrm{m})$ (a) Tangential stress distribution curve of the right sidewall

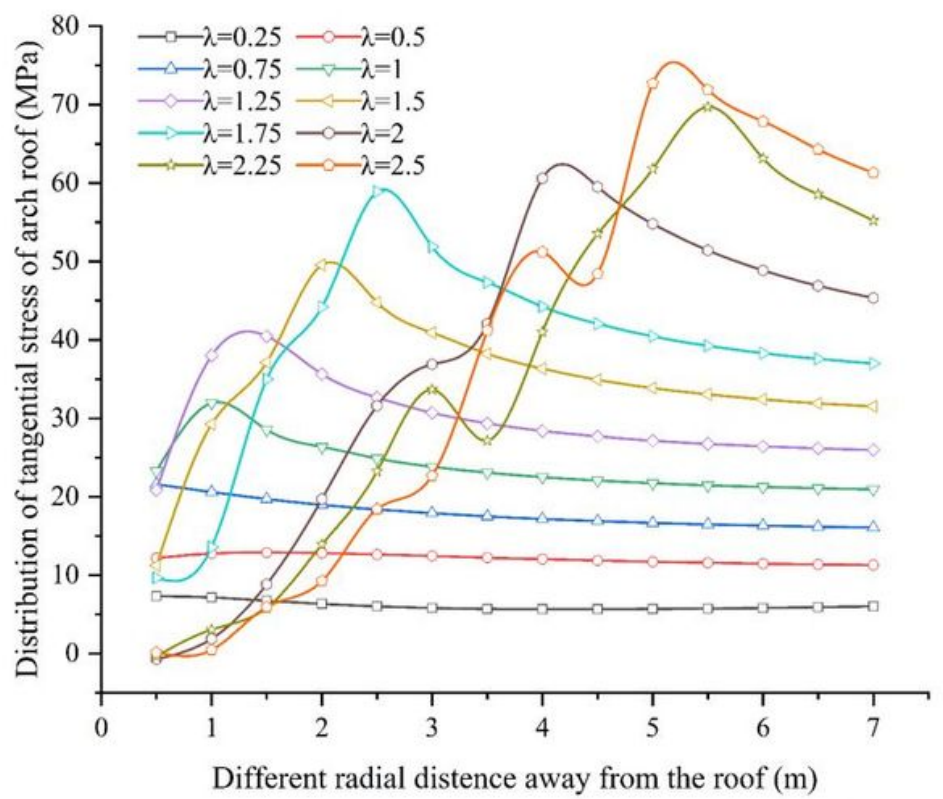

(b) Tangential stress distribution curve of the roof

\section{Figure 9}

Tangential stress curve distribution of roadway side and arch roof surrounding rock

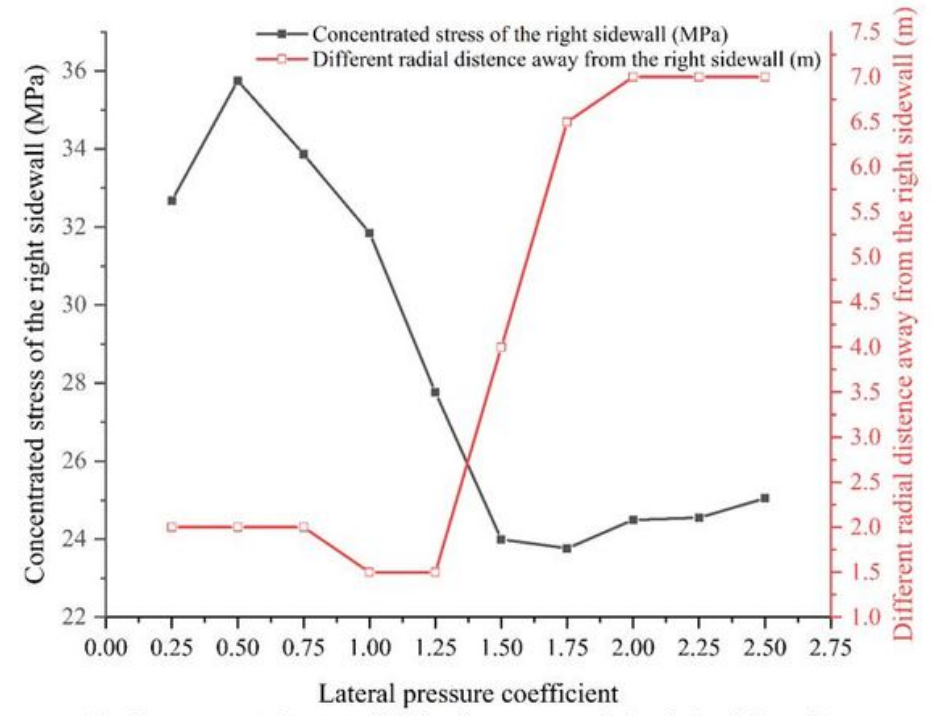

(a) Concentrated stress distribution curve of the right sidewall

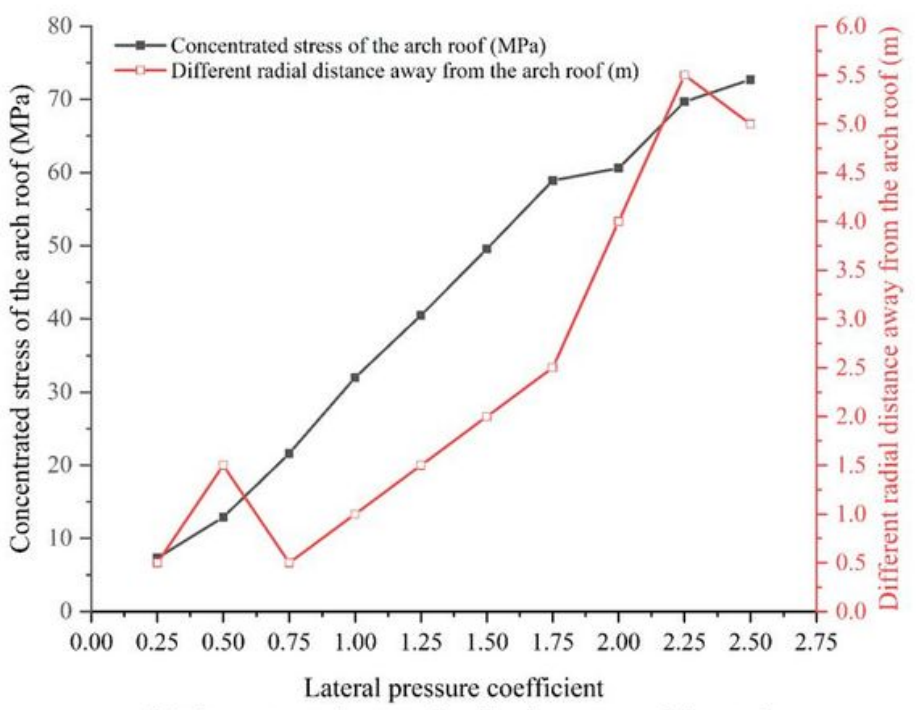

(b) Concentrated stress distribution curve of the roof

Figure 10

Distribution of peak stress with lateral pressure coefficient 


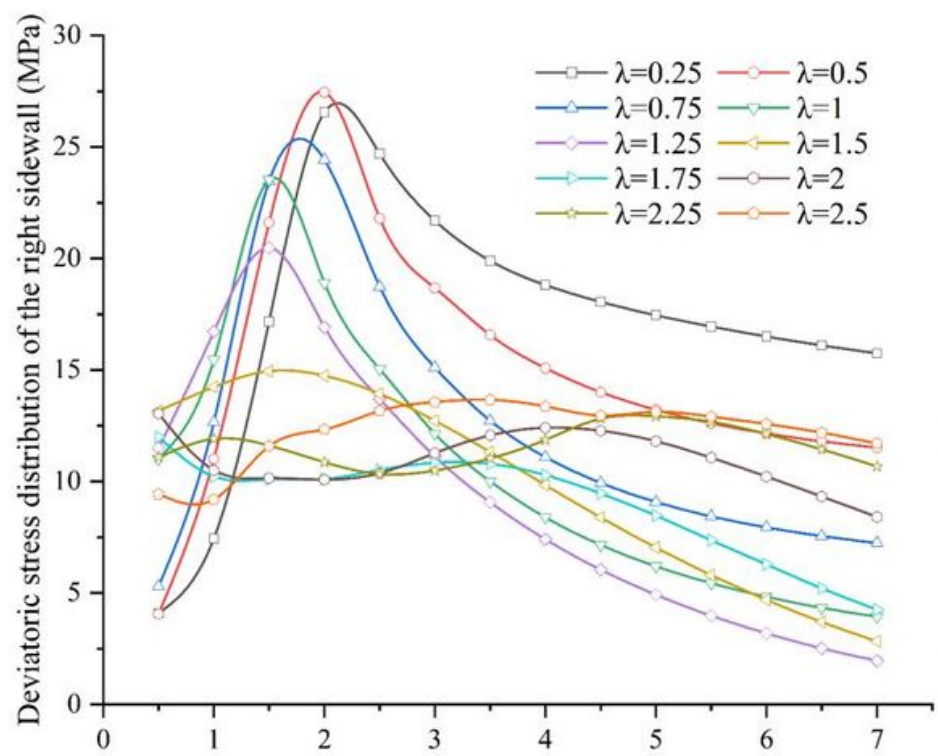

Different radial distence away from the right sidewall $(\mathrm{m})$

(a) Deviatoric stress distribution curve of the right sidewall

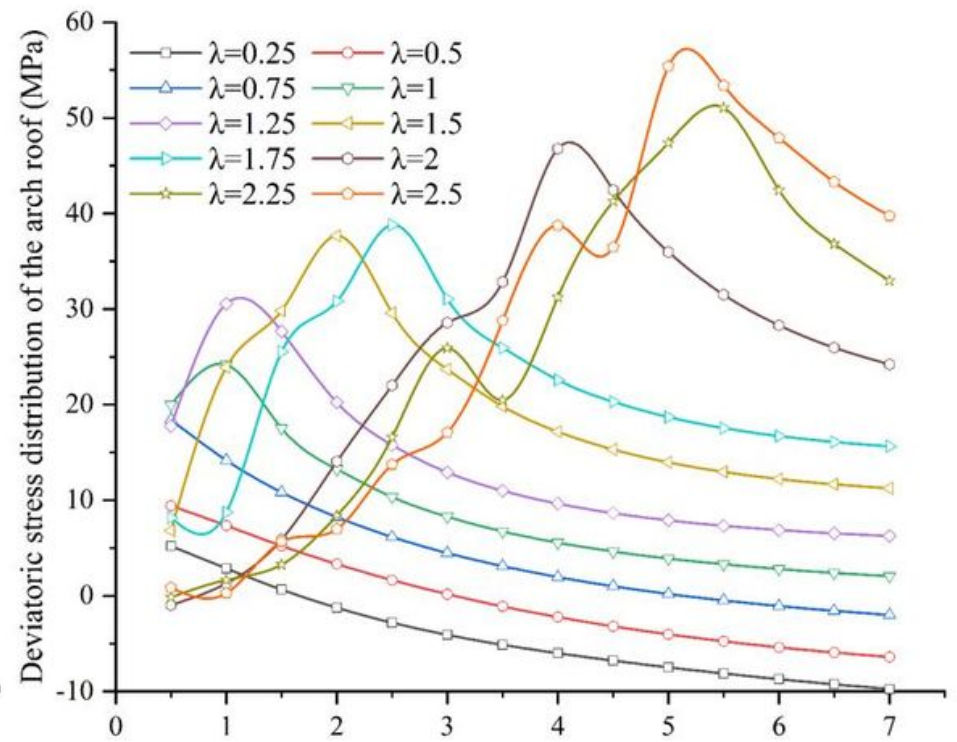

Different radial distance away from the arch roof $(\mathrm{m})$ (b) Deviatoric stress distribution curve of the roof

Figure 11

Distribution of deviatoric stress curve of the right sidewall and roof

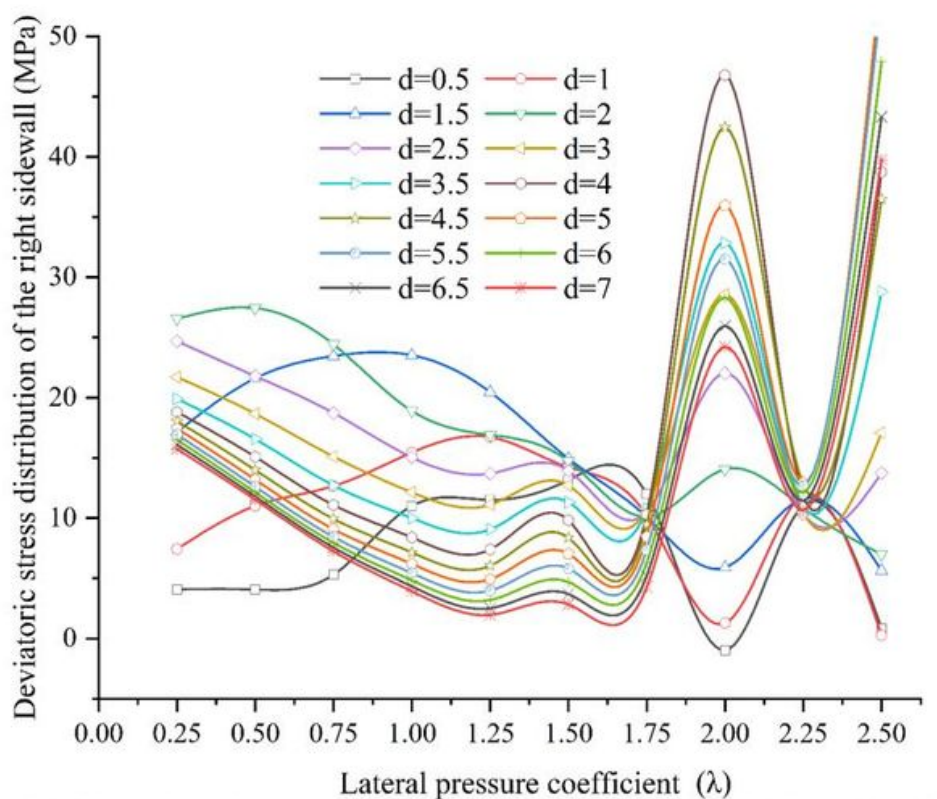

(a) The deviatoric stress curve in different distance of right sidewall

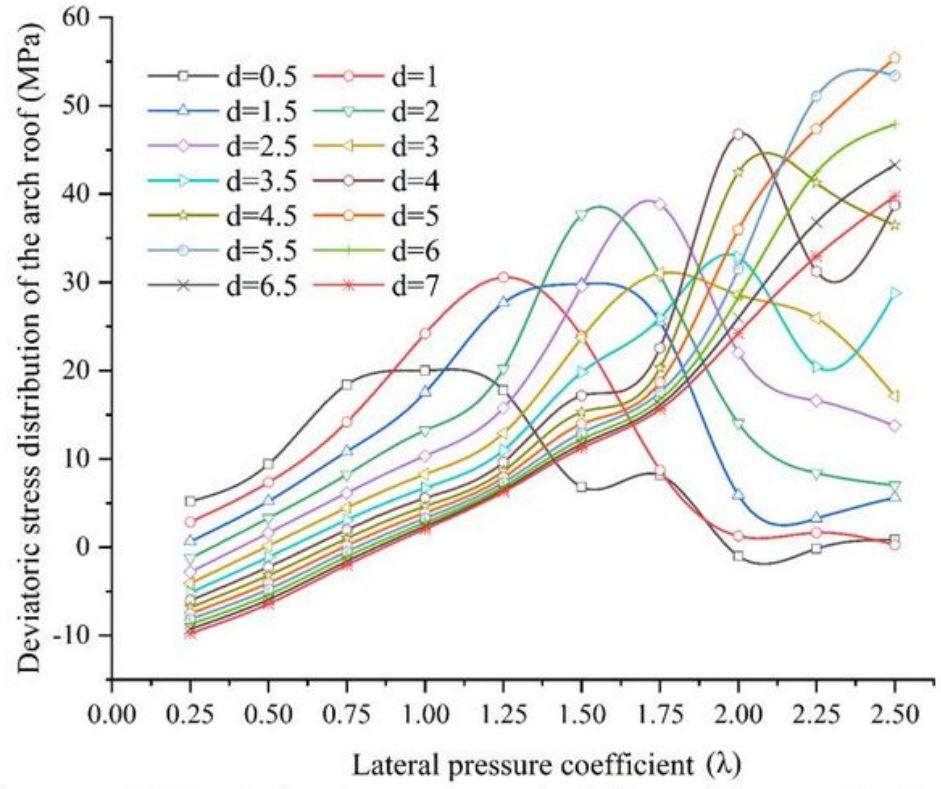

(b) The deviatoric stress curve in different distance of roof

Figure 12

Variation curve of deviatoric stress with the different distance away from the roadway 


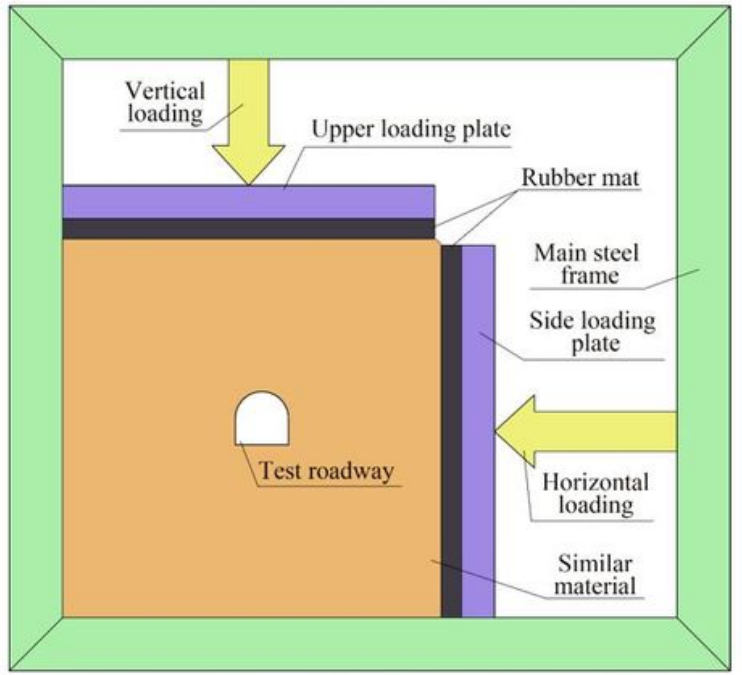

(a) Schematic diagram of experiment device

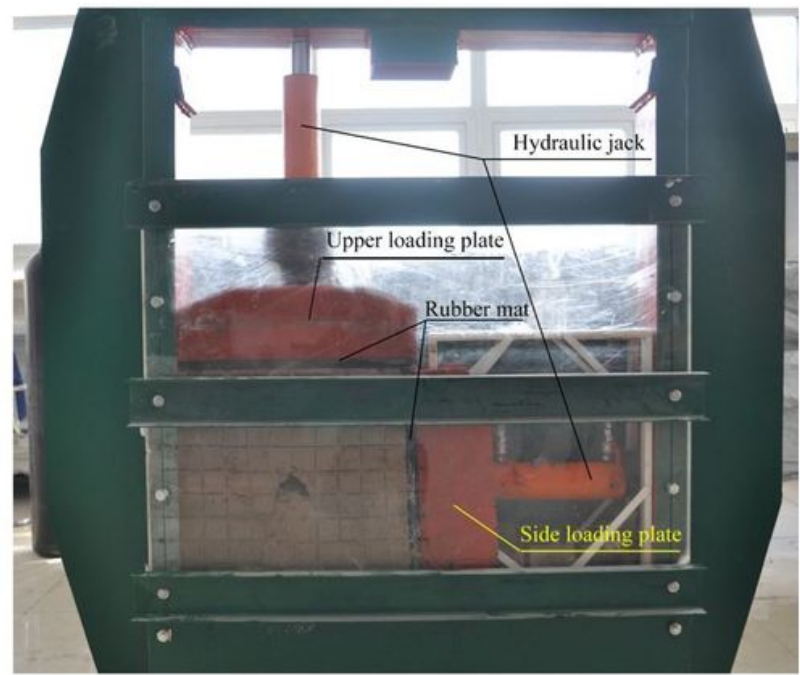

(b) Real figure of experiment device

Figure 13

Similar simulation experiment device

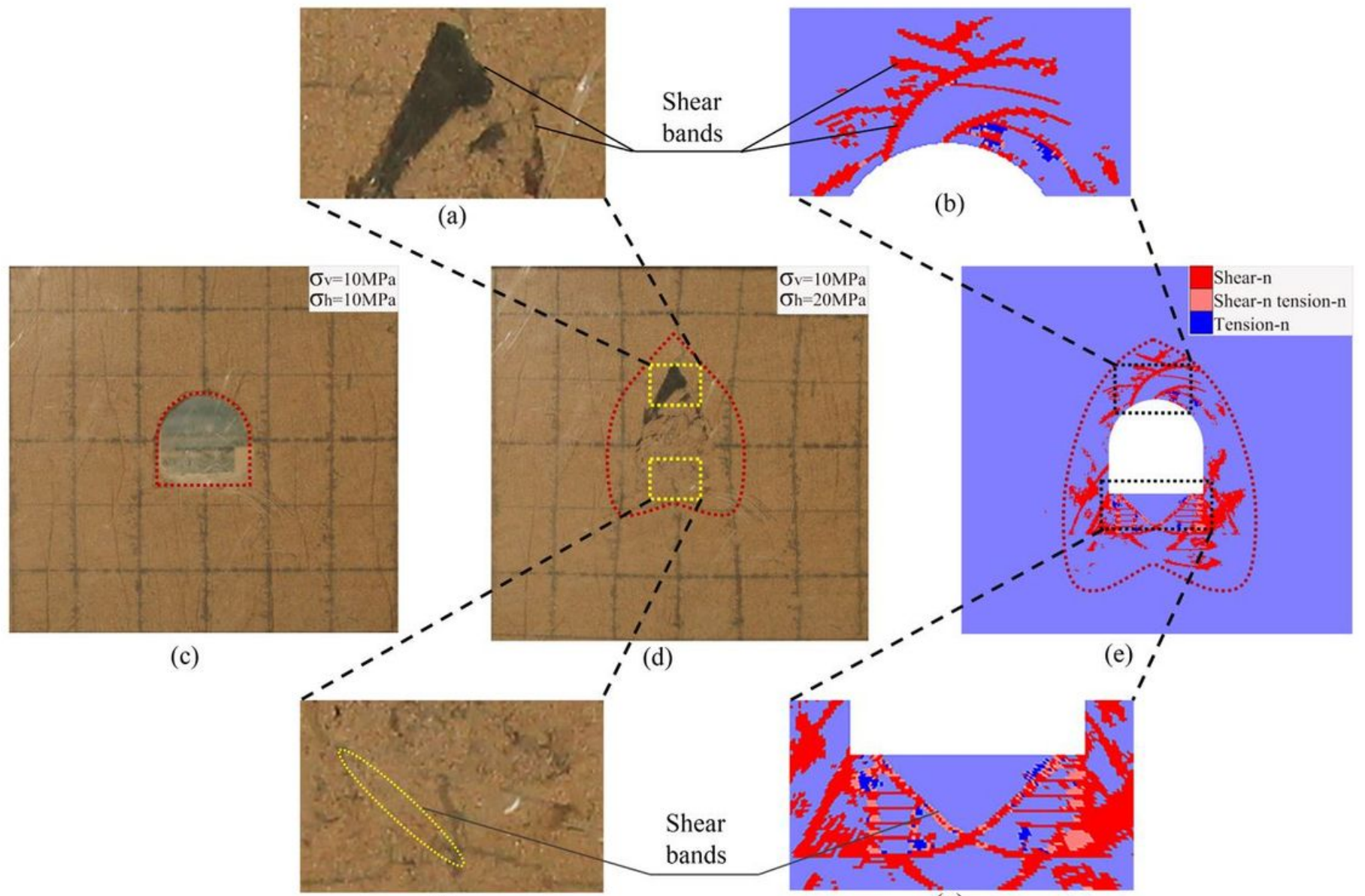

(f)

(g)

\section{Figure 14}

Comparison between physical experiment and numerical simulation experiment 